UDC 615.12.477: 615.2:628.474/475

DOI: $10.15587 / 2519-4852.2021 .225220$

\title{
PROBLEM OF ANTIBIOTICOREZISTENCE IN APPLICABLE ASPECTS OF ECOPHARMACY
}

\author{
Alla Kotvitska, Natalia Tsubanova, Nadiia Kononenko, Victoria Zurenko, Inna Andrusovich, \\ Valentyna Chikitkina
}

The aim. The aim of the work was to analyze the pharmaceutical fragments as components of the global problem of antibiotic resistance, to evaluate this aspect from the point of view of applied ecopharmacy and to propose solutions to this issue.

Materials and methods. Research materials - the results of a survey of pharmacy specialists. Analytical-comparative, system, logical, mathematical-statistical methods and the method of expert survey of specialists were used. At the first stage of the study, an expert survey of practical pharmacy workers was conducted in order to identify fixed points of correlation between such components as "practical pharmacy» - «antibiotic resistance» - «ecopharmacy». The second stage included the identification of positions at which it is necessary to develop additional informational training activities aimed at reducing antibiotic resistance.

Results. According to the results of an expert survey of specialists of the pharmaceutical sector of Ukraine (Kharkiv, Poltava, Vinnytsia, Chernihiv regions) on key issues of antibiotic resistance from the position of ecopharmacy, it was established that over $90 \%$ of antibacterial drugs are sold without a prescription and are not accompanied by adequate pharmaceutical care. The awareness of pharmacy specialists of the potential dangers from uncontrolled intake of antibacterial drugs rises with an increase in their level of professional competence. Not one of the respondents during the release of an antibacterial drug does not indicate how to dispose of the remaining doses of the drug, what danger does the improper utilization of unsuitable antibiotics to the ecosystem of the region.

Conclusions. According to the results of the research conducted among practical pharmacy experts, conclusions can be drawn about the low level of awareness of the impact of antibacterial drugs on the ecology of the environment; identified key positions for which additional information is needed (antibiotic resistance, ecopharmacy, pharmaceutical care), not only in the form of planned advanced training courses, but also additionally in the format of distance education, seminars, conferences

Keywords: antibiotic resistance, method of expert survey, ecopharmacy

(C) The Author(s) 2021

This is an open access article under the CC BY license (http://creativecommons.org/licenses/by/4.0).

\section{Introduction}

Antibiotic resistance has become the most problematic issue of modern medicine over the past decade, which represents a significant threat to human health and life, and radical measures are needed to reduce the risks associated with the resistance genes to antibiotics. Antibiotic-resistant bacteria withstand the inhibitory effect of one or even several antibiotics at maximum therapeutic doses, which significantly reduces the success of treatment, even for «common» infectious diseases (pneumonia, angina), which leads to significant social and economic costs for human well-being and health [1].

Monitoring of antibiotic resistance and determining its correlation with environmental pollution is one of the goals of the World Health Organization's global plan. The plan, which aims to reduce antibiotic resistance on a global scale, is aimed at combating antibiotic resistance in all areas of human interaction with the drug (antibiotic), and also takes into account the environmental impact of medicines [2].

The largest study was conducted in the period of autumn 2015 - autumn 2016, in seven European countries (Portugal, Spain, Ireland, Cyprus, Germany, Finland and Norway) was published in 2019. It included the determination of more than 50 antibiotic residues in wastewater, analysis of 229 resistance genes and 25 mobile genetic elements [3].

This first trans-European observation showed that the Cities wastewater treatment plants were recognized as one of the most important ways of spreading human resistance to antibiotics, due to the fact that unsuitable drugs or their metabolites are eliminated by the patient, get into the environment and city sewage [4]. Authors team found that the concentration profiles of antibiotics in wastewater reflect the gradient of antibiotic resistance observed in clinics. The relationship between the relative amount of antibiotics in wastewater and the phenotypic resistance of clinical isolates of common infectious agents to antibiotic therapy has been established.

Presence of antibiotic resistance genes in ecosystems such as activated sludge, wastewater, and surface water has been analyzed by metagenomic methods based on high-throughput sequencing.

Quantitative analysis of antibiotic-resistant genes was carried out by using an array of quantitative polymerase chain reactions and aimed at identifying the sequence of the genetic array involved in gene transfer and recombination; 25 mobile genetic elements were found that provide integrase, transposase, insertion sequence, and plasmid replicon type; antibiotics in wastewater 
induce a genetic change in the ecosystem microbiome, which forms antibiotic resistance genes $(n=229)$, including multidrug resistance gene $(n=39)$.

Results of the study, not only established a close relationship between clinical and environmental resistance to antibiotics, but also demonstrated the importance of taking social factors into account when developing possible strategies to control antibiotic resistance.

Similar results of the importance of the different stages of the use of antibacterial drugs, ecosystem disturbance and the formation of antibiotic resistance in patients from different countries are given in the publications of Manaia C. M. (2018), Sundberg L. R., Karvonen A. (2018) and other authors [5-9].

New interdisciplinary direction - ecopharmacy [10], which to some extent combines pharmacy, medicine, ecology, chemistry; covers all links of the «life» of a medicinal product, from its production to the disposal of unsuitable drugs, and also makes it possible to assess the impact of the medicinal product on the human ecosystem and the ecology of the environment.

In Ukraine, there is currently no strict medical monitoring of the use of antibacterial drugs, and no system for collecting unsuitable drugs from the public.

The aim of the work was to analyze the pharmaceutical fragments of the problem of antibiotic resistance, evaluate this aspect from the point of view of applied ecopharmacy and suggest ways to solve this issue.

\section{Planning (methodology) of research}

Antibiotic use is a key factor in increasing antibiotic resistance, and there is a correlation between antibiotic use and the level of resistance in a given country. It is predicted that by 2025, many first-line antimicrobial drugs will lose their effectiveness, which will initiate a «post-antibiotic era» [11]. Given the accelerating growth of antimicrobial resistance and the proliferation of multidrug-resistant bacteria, it can be expected that the treatment of common infections and the safe performance of simple surgical procedures will become increasingly difficult [12]. It is estimated that by 2050, drug-resistant infections - including bacterial, viral, fungal and parasitic ones - could lead to an increase in overall mortality by ten million cases per year [13].

It is advisable to conduct an expert survey at the beginning of a comprehensive study: to determine the goals, problem field and tools for the subsequent stages of the research project. An expert survey or a survey of specialists is a special method of sociological research. As part of such a survey, the topic under study is discussed with experts who are competent in this field. In our work, these were workers of practical pharmacy: pharmacists and heads of pharmacies. An expert survey is a type of quantitative research that involves deep elaboration of questions and cooperation between the interviewer and the expert.

The next stage was to identify positions for which it is necessary to develop additional information and training activities aimed at reducing antibiotic resistance.
The processing and analysis of information went through the following stages: fixing the results of the surveys, building reports based on the results of the questionnaire, and conducting the analysis.

\section{Materials and methods}

Research materials - results of a survey of pharmacy specialists. Analytical-comparative, system, logical, mathematical-statistical methods and the method of expert survey of specialists were used.

At the first stage of the study, an expert survey of practical pharmacy workers was conducted in order to identify fixed points of correlation between such components as «practical pharmacy» - «antibiotic resistance»«ecopharmacy».

The second stage included the identification of positions at which it is necessary to develop additional informational training activities aimed at reducing antibiotic resistance. The study was conducted in February - March 2019. As respondents 120 workers of practical pharmacy (pharmacy sector) took part in the study, namely, pharmacists and heads of pharmacy institutions. The study was conducted in Kharkiv, Poltava, Chernihiv and Vinnitsa regions of Ukraine.

Processing and analysis of information took place in the following stages: recording the results of surveys conducted, building reports on the results of the survey, and conducting analysis. For processing and analyzing the survey results was used StatPlus statistical analysis program, version 6. AnalystSoft Inc., developed by A. Simachev and licensed specifically for medical and sociological research [14].

\section{Results}

Table 1 shows the socio-demographic indicators of the sample of respondents.

Table 1

Socio-demographic indicators of study participants $(n=120)$

\begin{tabular}{|c|c|}
\hline Category & $\begin{array}{c}\text { Number of respondents } \\
(\%)\end{array}$ \\
\hline Gender characteristic & $21(17.5 \%)$ \\
\hline Men & $99(82.5 \%)$ \\
\hline Women & $31(26 \%)$ \\
\hline Age & $36(30 \%)$ \\
\hline $31-30$ & $34(28 \%)$ \\
\hline $41-50$ & $17(14 \%)$ \\
\hline $51-60$ & $2(2 \%)$ \\
\hline 61-70 and more & $43(36 \%)$ \\
\hline Education & $77(64 \%)$ \\
\hline Secondary special (pharmacist) & \\
\hline $\begin{array}{c}\text { Higher education (pharmacist, } \\
\text { clinical pharmacist })\end{array}$ & $16(13 \%)$ \\
\hline $\begin{array}{c}\text { Work experience in the } \\
\text { pharmacy }\end{array}$ & $26(21 \%)$ \\
\hline Up to 1 year & $18(16 \%)$ \\
\hline From 1 to 5 years & $60(50 \%)$ \\
\hline From 6 to 10 years & \\
\hline More than 10 years & \\
\hline
\end{tabular}


At the preliminary stage of analysis of the questionnaires, it was necessary to establish the level of competence of the respondents according to a number of basic criteria (education, practical work experience, availability of qualification category, systematic training courses), they categorized into 5 groups according to the level of competence $(\mathrm{k})$ : «Very low competence» $(\mathrm{k} 1)$; «Low» (k2); «Satisfactory» (k3); «High» (k4); «Very high» (k5). Data from expert questionnaires with compe- tence levels (k2-k5) were used later. The questionnaires with the k1 level «Very Low Competence» were recognized as invalid, there were 16 such questionnaires (13\% of the total), these were respondents working in the «pharmacist» position with work experience up to 1 year.

In order to assess level of influence of the pharmaceutical sector on the growth of antibiotic resistance during self-treatment, we figured out how antibiotics are sold at the pharmacy. The results are shown in Fig. 1.

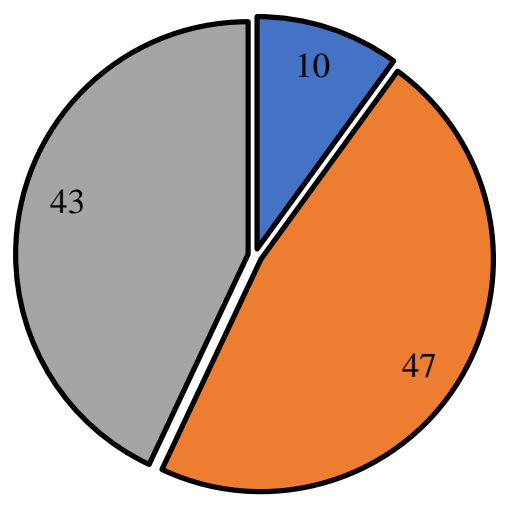

口prescription only

口very rare prescription

口never seen a recipe

Fig. 1. The release of antibacterial drugs in the pharmacy, $\%$

As can be seen from the obtained data (Fig. 1), only at $10 \%$ of cases, the supply of an antibacterial drugs to pharmacies takes place exclusively by prescription, in $90 \%$ of pharmacy workers or very rarely see a prescription and release it or the antibiotic release occurs in an alternative way, this is most often the record on a piece of paper, the verbal requirement of the buyer or the recommendation of the pharmacist himself after a brief conversation.

It should be noted that prescription antibiotics are produced mainly by respondents with a high level of competence. The decline in professional competence positively correlates with over the counter and, accord- ingly, uncontrolled sale of antibacterial drugs, most often these are drugs from the group of penicillins, cephalosporins and aminoglycosides.

Pharmaceutical support in the implementation of an antibacterial preparation is accompanied by compulsory pharmaceutical care in $60 \%$ of cases, $22 \%$ of respondents conduct pharmaceutical care if they have questions from the buyer, and in $18 \%$ of cases, pharmaceutical workers believe that pharmaceutical care should be done by a doctor.

An interesting factor is the components of the pharmaceutical support of the antibiotic (Fig. 2).

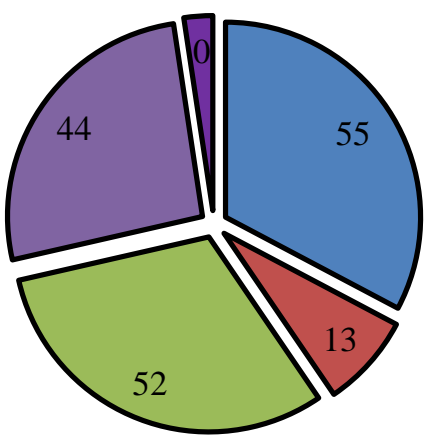

$\mathbf{0}$ drug dosage recommendations

口chronopharmacological recommendations

口be sure to take the entire specified period

口recommendation of additional pharmacotherapy

Fig. 2. Pharmaceutical worker recommendations when dispensing antibacterial drugs

Most of the pharmaceutical support of an antibacterial drug includes recommendations on dosage (55 respondents), duration of administration (52 respondents), use of additional pharmacotherapy (44 respondents), and even chronopharmacological features (13 respondents). At the same time, not one of the participants in this sociological experiment did not indicate to the buyer what to do with the remnants of an antibacterial drug, or with those antibiotics that are stored at home and that have expired.

Additionally, it was studied which drugs, with include of trademarks, are recommended by pharmacists 
when releasing an antibacterial drug. It has been established that probiotics occupy leading positions in the recommendations.

By analyzing answers of the respondents, we can conclude that such probiotics (Enterohermine, Enterol) recommended less than $8 \%$. Practicing pharmacy spe- cialists, due to lack of knowledge, recommend dietary supplements or drugs with insufficient CFU.

At the next stage, we studied the awareness of the pharmaceutical workers themselves about the risks and threats from the uncontrolled use of antibacterial drugs (Table 2).

Table 2

The level of awareness of pharmacy specialists about the dangers of uncontrolled intake of antibacterial drugs $(\mathrm{n}=104)$

\begin{tabular}{|l|c|c|c|c|c|c|}
\hline \multirow{2}{*}{ Dangers of uncontrolled antibiotics } & \multicolumn{3}{|c|}{ Competence level of respondents } & \multirow{2}{*}{ Total } & $\begin{array}{c}\% \text { of the number } \\
\text { of respondents }\end{array}$ \\
\cline { 2 - 6 } & $\mathrm{k} 2$ & $\mathrm{k} 3$ & $\mathrm{k} 4$ & $\mathrm{k} 5$ & & 74 \\
\hline Side effect (dysbiosis) & 8 & 8 & 34 & 26 & 74 & 23 \\
\hline Hepatotoxicity & 2 & 7 & 8 & 7 & 24 & 40 \\
\hline Development of antibiotic resistance & 2 & 4 & 22 & 14 & 42 & 0 \\
\hline $\begin{array}{l}\text { Environmental pollution by metabolites and/or } \\
\text { unsuitable antibiotics }\end{array}$ & 0 & 0 & 0 & 0 & 0 & 0 \\
\hline
\end{tabular}

The awareness of pharmacy specialists of the potential dangers from uncontrolled intake of antibacterial drugs increases with an increase in their level of professional competence, which can be clearly seen in the «Danger of development side effects (dysbiosis)» and «Danger of developing antibiotic resistance» points. The most problematic for the respondents was «Environmental pollution by metabolites and/or unsuitable antibiotics». Zero awareness of pharmacy specialists in this matter may be one of the important components of the problem of uncontrolled intake of antibiotics, environmental pollution with antibiotics and, accordingly, an increase in antibiotic resistance.

To break this vicious circle of «uncontrolled intake of antibiotics -environmental pollution by antibiot-

ics - antibiotic resistance» it can be achieved through information and training methods aimed at increasing the level of awareness of pharmacy specialists on applied ecopharmacy and antibiotic resistance.

In the framework of this study, we monitored the subjective needs of pharmacy specialists in information blocks, the lack of which they have in their practical activities (Table 3 ).

By analyzing the subjective needs of pharmacy specialists, it can be concluded that the most sought-after information areas are Pharmaceutical Care $(64 \%)$ and Improving Drug Safety (65\%). Moreover, the demand for these areas does not decrease with the growth of "formal" professional competence (work experience, continuous training courses, etc.).

Table 3

Information that is lacking in practical activities by pharmacy specialists (in their own opinion) $(\mathrm{n}=104)$

\begin{tabular}{|l|c|c|c|c|c|c|}
\hline \multirow{2}{*}{ The dangers of uncontrolled antibiotics } & \multicolumn{3}{|c|}{ Competence level of respondents } & \multirow{2}{*}{ Total } & $\begin{array}{c}\text { \% of the number of } \\
\text { respondents }\end{array}$ \\
\cline { 2 - 6 } & $\mathrm{k} 2$ & $\mathrm{k} 3$ & $\mathrm{k} 4$ & $\mathrm{k} 5$ & & 64 \\
\hline Pharmaceutical custody & 3 & 12 & 30 & 22 & 67 & 65 \\
\hline Improving drug safety & 7 & 13 & 32 & 16 & 68 & 11 \\
\hline Organization and management of pharmacy & 0 & 0 & 4 & 8 & 12 & 9 \\
\hline Aspects of legal activity & 0 & 2 & 4 & 4 & 10 & \\
\hline
\end{tabular}

Economic and legal blocks of information are not so important for pharmacy workers, and become relevant only when they are appointed to senior positions (pharmacy managers, deputy head, etc.).

Not one of the respondents noted that he needed information on the effects of drugs on the human ecosys- tem, the ecosystem of the locality, country, planet, although this question was open (you could write your own answer) and did not limit the number of response options.

In this study, it was analyzed which training format is the most optimal for respondents (Fig. 3).

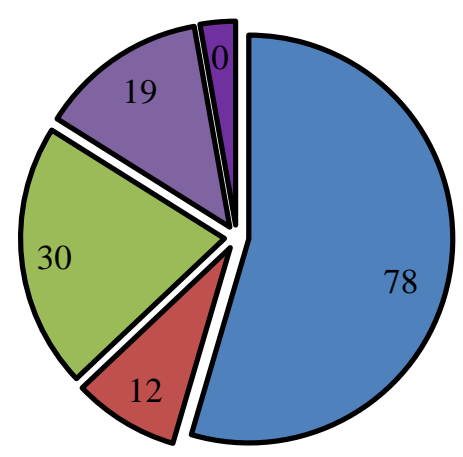

$\boldsymbol{\square}$ official advanced training events
$\boldsymbol{\square}$ workshops from pharmaceutical
manufacturers
$\boldsymbol{\square}$ distance education at universities

Fig. 3. Preferred training format for pharmacy specialists (each respondent could choose several answers) 
As can be seen (Fig. 3), the majority of respondents prefer the official (state) advanced training events as a source for obtaining new knowledge and learning new practical skills.

\section{Discussion}

At the present stage, antibiotic resistance poses a threat not only to human health, but also a serious problem of the state of the environment. The emergence of antibiotic-resistant bacteria in biosystems, especially in countries with their uncontrolled use, has become a global phenomenon and requires a reassessment of existing knowledge and dissemination to relevant audiences. An effective solution to this problem can only be purposeful complex actions and cooperation of professionals and scientists from various fields of science, including pharmacy [15]. At the same time, the level of competence of the pharmacist and his ability to carry out pharmaceutical care is of great importance.

The results of our study revealed a lack of knowledge and action on the part of pharmacy specialists in matters of antibiotic disposal. Moreover, the sale of antibiotics without a prescription (in Ukraine - $90 \%$ ), which is typical for low- and middle-income countries, may correlate with large volumes of antibiotic storage by consumers, as a result of which it is associated with a higher risk of environmental pollution by antimicrobial drugs.

An expert survey of specialists in the pharmaceutical sector also showed a positive aspect accompanying the dispensing of antibiotics, namely, recommendations for taking probiotics. It should be noted that the probiotic drug must comply with international guidelines [16]:

- registered as a drug,

- contains at least 1 billion colony forming units (CFU),

- the strain that is part of the probiotic is registered in official or international collections (ATCC collections);

- the strain has been accredited «safe» (GRAS) from the United States Food and Drug Administration (FDA) or has a status of «Qualified presumption of safety» from the European Food Safety Authority (EFSA);

- have clinical studies.

However, the insufficient level of knowledge of the staff of the studied pharmacies does not always lead to recommendations for effective probiotics.

It was found that, along with being aware of the serious medical consequences of uncontrolled intake of antibiotics (antibiotic resistance, adverse reactions, hepatotoxicity), specialists in the pharmaceutical sector of all surveyed institutions have no idea about possible environmental pollution by metabolites and / or unsuitable antibacterial drugs. Consequently, the results obtained indicate the relevance and feasibility of increasing the level of knowledge of pharmaceutical specialists in the field of environmental safety. It should be noted that in the literature we studied, there is no data on the experience of raising awareness among pharmacy staff regarding the relationship between antibiotic resistance and environmental pollution. In our opinion, the training of pharmacists in the theoretical and practical aspects of ecopharmacy may affect the reduction of e-antibiotic resistance.

The theoretical component of training of pharmacy specialists should include the following information blocks:

- main aspects of new interdisciplinary direction ecopharmacy;

- ecopharmacological portrait of the drug;

- ecopharmacotherapy.

Practical aspects of ecopharmacy should be directed to an effective monitoring system for the disposal of unsuitable antibacterial drugs.

Information component should include the following items:

Antibacterial drugs should be released only by prescription. Pharmacy specialists do not have the authority to recommend antibiotics on their own, as they are unable to provide medical services (correct diagnosis, assessment of the severity of the disease, the presence of concomitant diseases and, accordingly, interaction with the medications used). Sale of antibiotics exclusively by prescription will completely solve the problem of selftreatment and uncontrolled intake of this group of drugs).

Pharmaceutical specialists during prescription of an antibacterial drug must indicate its effect on the body's ecosystem and recommend probiotic medications.

When selling antibiotics, it is necessary to inform the buyer how and where to dispose of the remnants of the drug or drugs that are stored in the home medicine cabinet and which have expired.

As can be seen from the above, the urgent need today is the introduction of training information events for pharmaceutical workers, containing information materials on ecopharmacy and its relationship with antibiotic resistance.

This means that an educational campaign aimed at raising awareness of pharmacists about European and global experience in handling pharmaceutical waste and ensuring proper disposal of unnecessary medicines from the public, increasing the literacy of pharmaceutical support for an antibacterial drug, and optimizing pharmaceutical care should be included at the postgraduate stage of training pharmacy specialists.

A promising direction could be training, in which all the material for reducing antibiotic resistance and building awareness on key ecopharmacy positions would be presented in an interactive form.

Study limitation. The study included a limited number of employees involved in practical pharmacy

Prospects for further researches. Further actualization of the problem of antibiotic resistance among pharmacy specialists and the promotion of the idea of a responsible attitude to the implementation of an antibacterial drug are necessary. A promising direction of our research is the introduction of applied aspects of ecopharmacy into the professional activities of pharmacists. Formation of social responsibility and the launch of existing programs for the implementation of ecopharmacy can change the problematic situation of environmental pollution with antibiotics, disruption of the ecosystem of the human body and the development of antibiotic resistance. 


\section{Conclusions}

1. One of the weighty reasons for the growth of antibiotic resistance is the increase in the use of antibacterial drugs, the major components of which can be considered over-the-counter selling of drugs of this group at the pharmacy level and the uncontrolled intake of patients during self-treatment.

2. An effective approach in order to break the circle of «uncontrolled intake of antibiotics - environmental pollution by antibiotics - antibiotic resistance» is the introduction of information-training methods of ecopharmacy. The introduction of ecopharmacy will reduce environmental pollution with antibiotics and/or their metabolites, provided proper disposal of unsuitable drugs and/or their residues.

3. It is necessary to include data on ecopharmacy in educational programs at the postgraduate stage, as well as in information and training activities of various organizers for pharmacy specialists, in particular to reduce antibiotic resistance.

\section{Conflict of interests}

The authors declare that they have no conflicts of interest.

\section{References}

1. Berendonk, T. U., Manaia, C. M., Merlin, C., Fatta-Kassinos, D., Cytryn, E., Walsh, F. et. al. (2015). Tackling antibiotic resistance: the environmental framework. Nature Reviews Microbiology, 13 (5), 310-317. doi: http://doi.org/10.1038/nrmicro3439

2. WHO, Global antimicrobial resistance surveillance system (GLASS) report: Early implementation 2016-2017 (2018). Geneva: WHO, 164. Available at: www.who.int/glass/resources/publications/early-implementation-report/en/

3. Pärnänen, K. M. M., Narciso-da-Rocha, C., Kneis, D., Berendonk, T. U., Cacace, D., Do, T. T. et. al. (2019). Antibiotic resistance in European wastewater treatment plants mirrors the pattern of clinical antibiotic resistance prevalence. Science Advances, 5 (3), eaau9124. doi: http://doi.org/10.1126/sciadv.aau9124

4. Berendonk, T. U., Manaia, C. M., Merlin, C., Fatta-Kassinos, D., Cytryn, E., Walsh, F. et. al. (2015). Tackling antibiotic resistance: the environmental framework. Nature Reviews Microbiology, 13 (5), 310-317. doi: http://doi.org/10.1038/nrmicro3439

5. FIP statement of policy: Environmentally sustainable pharmacy practice: Green pharmacy (2016). Buenos Aires, 3. Available at: https://www.fip.org/file/1535

6. Barnett-Itzhaki, Z., Berman, T., Grotto, I., Schwartzberg, E. (2016). Household medical waste disposal policy in Israel. Israel Journal of Health Policy Research, 5 (1). doi: http://doi.org/10.1186/s13584-016-0108-1

7. Bashaar, M., Thawani, V., Hassali, M. A., Saleem, F. (2017). Disposal practices of unused and expired pharmaceuticals among general public in Kabul. BMC Public Health, 17 (1). doi: http://doi.org/10.1186/s12889-016-3975-z

8. Manaia, C. M., Rocha, J., Scaccia, N., Marano, R., Radu, E., Biancullo, F. et. al. (2018). Antibiotic resistance in wastewater treatment plants: Tackling the black box. Environment International, 115, 312-324. doi: http://doi.org/10.1016/j.envint.2018.03.044

9. Sundberg, L.-R., Karvonen, A. (2018). Minor environmental concentrations of antibiotics can modify bacterial virulence in co-infection with a non-targeted parasite. Biology Letters, 14 (12), 20180663. doi: http://doi.org/10.1098/rsbl.2018.0663

10. Kotvitska, A. A., Tsubanova, N. A., Kononenko, N. M., Ostapets, M. O. (2019). Formation and development perspectives of eco-pharmacy. Journal of Education, Health and Sport, 9 (2), 521-531. doi: http://dx.doi.org/10.5281/zenodo.2613883

11. Antibiotic Armageddon in UK and Europe by 2025 (2015). European Society of Clinical Microbiology and Infectious Diseases. 2015 Available at: https://www.biospace.com/article/releases/-b-escmid-b-release-antibiotic-armageddon-in-uk-and-europe-by-2025-/

12. Barriere, S. L. (2014). Clinical, economic and societal impact of antibiotic resistance. Expert Opinion on Pharmacotherapy, 16 (2), 151-153. doi: http://doi.org/10.1517/14656566.2015.983077

13. O'Neill, J. (2014). The Review on Antimicrobial Resistance: tackling a crisis for the health and wealth of nations. Available at: https://wellcomecollection.org/works/rdpck35v

14. AnalystSoft Inc., StatPlus is a statistical analysis program. Version 6. Available at: www.analystsoft.com/ru/

15. Felis, E., Kalka, J., Sochacki, A., Kowalska, K., Bajkacz, S., Harnisz, M., Korzeniewska, E. (2020). Antimicrobial pharmaceuticals in the aquatic environment - occurrence and environmental implications. European Journal of Pharmacology, 866, 172813. doi: http://doi.org/10.1016/j.ejphar.2019.172813

16. Polanco Allué, I. (2015). Microbiota and gastrointestinal diseases. Anales de Pediatría (English Edition), 83 (6), 443.e1443.e5. doi: http://doi.org/10.1016/j.anpede.2015.11.003

Received date 09.12.2020

Accepted date 18.02.2021

Published date 28.02.2021

Alla Kotvitska, Doctor of Pharmaceutical Sciences, Professor, Rector, National University of Pharmacy, Pushkinska str., 53, Kharkiv, Ukraine, 61002, E-mail: alla_kotvitska@ukr.net

Natalia Tsubanova, Doctor of Pharmaceutical Sciences, Professor, Department of Clinical Pharmacology, Institute for Advanced Training of Pharmacy Specialists, National University of Pharmacy, Pushkinska str., 53, Kharkiv, Ukraine, 61002, E-mail: tsubanova19@gmail.com

Nadiia Kononenko, MD, Professor, Head of Department, Department of Physiology and Pathological Physiology, National University of Pharmacy, Pushkinska str., 53, Kharkiv, Ukraine, 61002, E-mail: kononenkonn76@ gmail.com

Victoria Zurenko, Postgraduate student, Department of Management, Economics and Quality Assurance in Pharmacy, National University of Pharmacy, Pushkinska str., 53, Kharkiv, Ukraine, 61002, E-mail: zhur@nuph.edu.ua

Inna Andrusovich, Postgraduate student, Department of Infectious Diseases, Kharkiv Medical Academy of Postgraduate Education, Amosova str., 58, Kharkiv, Ukraine, 61176, E-mail: innaandrusovic@gmail.com

Valentyna Chikitkina, PhD, Associate Professor, Department of Physiology and Pathological Physiology, National University of Pharmacy, Pushkinska str., 53, Kharkiv, Ukraine, 61002 